\title{
O ANOITECER FEMINISTA DA PANDEMIA NO BRASIL ${ }^{1}$ Entrevista com Flávia Biroli
}

\author{
Lorena Lima de Moraes ${ }^{2}$ \\ UFRPE-UAST: http://orcid.org/0000-0002-8656-2412 \\ Andressa Lidicy Morais Lima ${ }^{3}$ \\ GPS-UFRN; CAJU-UnB: https://orcid.org/0000-0002-2232-0799
}

DOI: https://doi.org/10.21680/1982-1662.2020v3n28ID22555

\section{Resumo}

A presente entrevista com a cientista política Flávia Biroli faz parte do Dossiê “A Pandemia da Covid-19 na vida das mulheres”. Tomamos como questão central qual o impacto mais imediato desta pandemia sobre a vida das mulheres? A partir dessa questão, as demais perguntas foram elaboradas de forma a aprofundar e debater alguns temas relacionados à desigualdade de gêneros em diferentes contextos como os processos de cuidado, as jornadas contínuas de trabalho, as experiências de violência vivenciadas e o que podemos prospectar em relação a um futuro póspandemia.

1. Cara professora Flávia, esta entrevista faz parte do dossiê temático “A Pandemia da Covid-19 na vida de mulheres". A proposta geral do dossiê é reunir mulheres acadêmicas de lugares sociais diversos para refletir sobre o presente e o futuro no contexto atravessado pela crise sanitária provocada pela pandemia da Covid-19. Então, nossa aposta se embasa naquilo que cientistas sociais têm

\footnotetext{
${ }^{1} \mathrm{O}$ título dessa entrevista faz referência à resposta da última pergunta e também relaciona-se com um dado objetivo sobre um dos efeitos dessa pandemia recair de maneira imediata sobre a vida das mulheres: a colonização do espaço doméstico com jornadas contínuas de trabalho. Jornadas estas que produzem situação de exaustão em função de acúmulos de trabalho com cuidados (casa, filhos, maridos, idosos, familiares que foram acometidos pela covid-19, entre outras pessoas), conforme também podemos em algumas descrições e análises realizadas por autoras deste dossiê.

2 Email: lorena.moraes@ufrpe.br

3 Email: andmoraislima@gmail.com
} 
INTER-LEGERE | Vol. 3, n. 28/2020: c22555 | ISSN 1982-1662

refletido acerca de suas próprias vivências, mas também acerca do que estão observando como acontecimentos múltiplos e impactantes da nossa vida social. A resposta servirá de baliza para todas nós, uma vez que estamos com uma coletiva de mulheres escrevendo e refletindo sobre esta questão, sabemos que vamos encontrar diferentes pontos de vista e, vemos algo bom nisso, pois é a possibilidade de dar visibilidade a questões profundas sobre a vida de diferentes mulheres na pandemia da Covid-19. Sendo assim, conhecendo um pouco de sua produção e atuação na esfera pública brasileira, gostaríamos de ouvi-la sobre qual o impacto mais imediato desta pandemia sobre a vida das mulheres?

Obrigada pelas questões colocadas. É fundamental que esse debate proposto por vocês seja ampliado e que possamos produzir informações e refletir sobre os efeitos da pandemia numa perspectiva de gênero. No meu entendimento, levando em consideração o que conhecemos até este momento sobre os efeitos da pandemia, o impacto de gênero mais imediato é sobre as relações de trabalho e de cuidado. A pandemia pressionou ainda mais os circuitos privados do cuidado, com a suspensão do ensino presencial nas escolas e necessidade de cuidar das pessoas que adoecem. Pesquisas mostram que, em diferentes partes do mundo, a responsabilidade de cuidar das crianças e dos que adoecem tem sido atribuída predominantemente às mulheres. Mas há, ainda, um segundo aspecto. Como trabalhadoras informais e também como maioria entre as pessoas desempregadas, a crise econômica força mais mulheres à condição de vulnerabilidade econômica. Vale observar que as mulheres estão vivenciando a pandemia e seus efeitos de maneiras diferentes, de acordo com sua posição de classe, racial, geracional e também a depender de onde vivem. 0 acesso à saúde, por exemplo, depende das capacidades preexistentes do Estado - se há ou não um sistema de saúde pública capaz de dar respostas às necessidades neste momento, lembrando, ainda, que as mulheres são a maioria entre os profissionais de saúde, enfermeiras e técnicas, e são afetadas também como trabalhadoras pelas condições desse sistema. No que diz respeito ao trabalho, a resposta dos diferentes países à perda de empregos e ao empobrecimento também é uma questão fundamental, sobretudo quando pensamos que em muitos países, como é o caso no Brasil, entre os lares mais empobrecidos uma larga fatia é formada por mulheres com seus filhos. 
2. Parte de sua produção intelectual poderia estar situada no trinômio democracia, gênero e desigualdade. 0 contexto de crise sanitária nos trouxe desafios sobre o modo como existimos e interagimos. Entre as primeiras impressões da pandemia foi bastante comentado o aumento de $9 \%$ no volume de denúncias de casos de violência doméstica no período de confinamento recebidas pelo Disque $180^{4}$. De certo modo, esse dado traz para nós o desafio constante de refletirmos sobre os impactos de uma socialização ainda marcada por uma forte assimetria de gênero e um processo de reprodução sistemática da dominação masculina. Como a senhora avalia tais arranjos, ou melhor, podemos aventar a possibilidade de uma mudança estrutural sobre tais formas desiguais de relação? Ainda assim, nos interrogamos, sobre o fato da violência doméstica contra as mulheres e contra as meninas ter aumentado neste momento de distanciamento social e maior convívio com o agressor, sabendo que este dado se repete em vários países dos diversos continentes. Diante disso, como a senhora avalia a atuação do Ministério da Mulher, da Família e dos Direitos Humanos?

Nessa situação radicalmente nova da pandemia de Covid-19, revela-se muito sobre como as sociedades se organizam, sobre as formas preexistentes de desigualdades, de violência, de vulnerabilidade. Nos últimos cerca de 50 anos, os feminismos tiveram grande sucesso ao demonstrar que as relações de gênero são um problema político. Foi nesse processo, que tem como algumas marcos a "Convenção sobre a eliminação de todas as formas de discriminação contra a mulher" (CEDAW), aprovada em 1979 pela Assembleia Geral das Nações Unidas, e a Plataforma e Declaração de Beijing, de 1995, aprovadas na IV Conferência Mundial sobre a Mulher, fica estabelecido que é dever e responsabilidade do Estado o combate a essa violência. $\mathrm{E}$, claro, que sua manutenção compromete a cidadania das mulheres. $\mathrm{O}$ que a pandemia nos mostra, de maneira brutal, é que a violência é um motor de reprodução das hierarquias de gênero que pode ser ativado em diferentes circunstâncias. No cotidiano, permite a manutenção do controle sobre as mulheres,

\footnotetext{
${ }^{4}$ Ver: <https://oglobo.globo.com/sociedade/celina/damares-diz-que-denuncias-de-violencia-contramulher-aumentaram-9-durante-pandemia-24347077>.
} 
INTER-LEGERE | Vol. 3, n. 28/2020: c22555 | ISSN 1982-1662 a regulação do seu grau de autonomia. Demonstra a importância de se discutir abusos na esfera privada doméstica, onde ocorre a maior parte das agressões (que, em sua maioria, são cometidas por pessoas conhecidas das vítimas), algo que já era realidade antes da pandemia. No nível estatal, ainda que exista legislação relevante, como é o caso da Lei Maria da Penha, aprovada no Brasil em 2006, é preciso priorizar a prevenção e o combate. Seria preciso, por exemplo, atuar sobre as causas dessa violência, promovendo educação para a igualdade entre meninas e meninos, justamente o que tem sido atacado por governos de direita e de extrema-direita, em aliança com grupos conservadores religiosos. Sendo muito direta: em momentos em que a esfera privada familiar se torna mais abrangente na vida das pessoas, a violência contra as mulheres se amplia em todo o mundo? Isso mostra o quanto as relações de gênero, em seus padrões atuais, se confundem com o exercício do poder e da crueldade por parte de muitos homens. É preciso perguntar aos antifeministas se é essa a ordem familiar que buscam tão arduamente preservar. Em nome de que? De manter o exercício do domínio? Isso custa a dignidade e a vida para muitas, é preciso deixar muito claro.

3. Débora Thomé e Hildete Pereira de $\mathrm{Melo}^{5}$ ressaltam que ao longo da história ocidental, a guerra sempre foi um espaço quase exclusivo dos homens. A guerra, afirmam as pesquisadoras, é um campo narrativo no qual os homens transitam com naturalidade, enquanto às mulheres lhes resta o papel secundário ou de mera obediência às leis maiores. Na esfera da representação política, as mulheres representam apenas dez dos 153 chefes de Estado eleitos em 2018, de acordo com a União Interparlamentar, sabemos também que as chefes de estado têm dado boas respostas à crise sanitária 6 . A senhora pode comentar esta “metáfora da guerra" contra a pandemia da Covid-19 adotada em vários países, sobretudo, aqueles liderados por homens?

\footnotetext{
${ }^{5}$ Ver: < https://fes-minismos.com/a-pandemia-de-guerra-dos-homens/>.

6 Ver: <https://brasil.elpais.com/brasil/2020-05-02/a-luta-contra-o-coronavirus-tem-o-rosto-demulheres.html>.
} 
INTER-LEGERE | Vol. 3, n. 28/2020: c22555 | ISSN 1982-1662 Importante que tenham colocado essa questão. Em um momento em que é preciso apoio recíproco, suporte público e no qual a vulnerabilidade humana é tão explícita, prevalece nos noticiários e em pronunciamentos de governantes a ideia de que esta é uma guerra a ser vencida. Nas guerras, a lógica é antagônica e pode envolver a eliminação do outro. No enfrentamento da pandemia, deveríamos discutir como vivemos e como é possível preservar a vida, reduzir a dor e reproduzir as sociedades de maneira menos predatória. Isso é fundamental para se compreender o que produziu a pandemia - desequilíbrios ambientais estão sendo apontados como uma questão central - e em que condições lidamos com ela. No meu entendimento, deveríamos falar da erosão das solidariedades e da proteção social. Ela se deu de maneira lenta, ao longo de décadas, na medida em que a lógica neoliberal se tornou lógica de governo e racionalidade cotidiana. Produziu-se, assim, a percepção do econômico como esfera autônoma em relação à política, aprofundou-se uma noção de mérito que silencia sobre as condições desiguais de acesso a recursos e justifica as desigualdades e, importante neste momento, foi sendo minada a percepção do coletivo e reforçada a ideia de que ser livre é agir como se quer - é perder de vista o outro e o que podemos produzir e modificar coletivamente. Na resposta a uma crise sanitária e econômica como esta, o que temos a dizer sobre nossa capacidade de atuar coletivamente? 0 que temos a dizer sobre nossa capacidade de estabelecer relações de trabalho com alguma previsibilidade, reguladas de forma que permita garantir uma renda mínima e o cuidado de si e dos outros? A precarização do trabalho e a precarização da vida andam de mãos dadas, a redução do suporte público estatal (restringindo recursos em áreas básicas, como saúde e educação) vem, por sua vez, acompanhada da desregulamentação da preservação ambiental. É o contrário do que seria necessário para a proteção à vida, em condições justas.

4. A pandemia está aprofundando diversas feridas já presentes na nossa sociedade contemporânea, sobretudo aquelas que afetam diretamente e mais profundamente as mulheres. Recentemente foi compartilhado um dado que diz ser $85 \%$ dos serviços de enfermagem no Brasil praticados por profissionais mulheres $^{7}$, sabendo também que as mulheres representam $70 \%$ dos profissionais

\footnotetext{
${ }^{7}$ Ver: <http:/ / www.generonumero.media/enfermeiras-na-linha-de-frente-contra-o-coronavirus/>.
} 
INTER-LEGERE | Vol. 3, n. 28/2020: c22555 | ISSN 1982-1662 de saúde em todo o mundo ${ }^{8}$. Tais dados nos colocam diante de questões como a separação entre esferas públicas e privadas para homens e mulheres e uma divisão sexual do trabalho em que pese a sustentação de uma cadeia expressiva da experiência de cuidado com os outros como destino social pré-escolhido para mulheres. A psicóloga Carol Gilligan (1982) afirmou inclusive que parte desse entendimento de que o cuidado desperta um tipo de sensibilidade moral singular para mulheres, nos colocaria numa posição de valorizar uma ética do cuidado como algo substancialmente do feminino. Muitas feministas problematizaram tal percepção, no entanto, vemos parte dessa estrutura social de cuidado se reproduzir nos dados acima mencionados e com isso renovar os estereótipos de gênero. Mas, ainda assim, tal questão requer de nós uma análise mais atenta e com isso abrimos esse espaço para sua reflexão sobre este assunto. Em relação a esse trabalho de cuidado, pensando também o lar e as tarefas domésticas não remuneradas, que sobrecarregam as mulheres, a senhora acha que essas questões irão virar tema central em nossa sociedade? Como podemos amplificar este debate para além da academia?

Comentei antes que um dos impactos diretos da pandemia sobre as mulheres está relacionado à maior necessidade do cuidado dentro de casa. E sabemos, pelos dados que temos sobre o uso do tempo e por uma série de pesquisas qualitativas, que são as mulheres, predominantemente, que assumem esse trabalho. Precisamos nos perguntar por que é assim, levando em conta a importância do cuidado para todas as pessoas, no cotidiano. São convenções, como sabemos, mas é também apropriação do tempo, das capacidades. 0 apagamento do trabalho enquanto tal também é parte da reprodução dessas relações: apresentadas como naturalmente femininas.

5. Em abril deste ano, a senhora publicou um artigo na Folha de São Paulo onde faz uma reflexão sobre os efeitos da pandemia afetarem diferencialmente os indivíduos". Em certo trecho diz "Nossa condição comum de fragilidade e nosso

\footnotetext{
8 Ver: < https://g1.globo.com/bemestar/coronavirus/noticia/2020/04/19/como-a-pandemia-decoronavirus-impacta-de-maneira-mais-severa-a-vida-das-mulheres-em-todo-o-mundo.ghtml>.

9 Ver: < https://www1.folha.uol.com.br/opiniao/2020/04/novo-coronavirus-responsabilidade-eprecariedade.shtml>.
} 
INTER-LEGERE | Vol. 3, n. 28/2020: c22555 | ISSN 1982-1662 destino coletivo estão expostos pela pandemia. Ela nos pressiona a olhar criticamente para o neoliberalismo e seus efeitos" ${ }^{10}$. Nesse sentido, uma das questões que gostaríamos de refletir diz respeito às prospecções futuras, isto é, o que podemos imaginar para um contexto pós-pandemia acerca das estruturas sociais de gênero e de raça que informam, por exemplo, a manutenção de uma estrutura de trabalhos domésticos cuja principal responsável por esta gestão, à baixíssimo custo, tendo direitos trabalhistas limitados e alta vulnerabilidade socioeconômica é ainda a figura da mulher negra? Inclusive considerada atividade essencial pelo decreto recém publicado em pelo Governo do Pará ${ }^{11}$.

Penso que há duas linhas em que podemos pensar - e as tensões entre elas talvez sejam o mais promissor para a análise das possibilidades futuras. A primeira delas é a que já venho mencionando aqui: a pandemia e seus efeitos se somam a desigualdades preexistentes e podem, assim, ampliar a vulnerabilidade das pessoas que vivam em condições de insegurança sanitária, econômica e relativa à violência. 0 trabalho doméstico e o de cuidado se ampliam, a crise econômica pode ampliar o endividamento, reduzir as taxas e emprego e pressionar as contas públicas, justificando restrições orçamentárias. Veja que, em meio a tudo isso, a discussão da reforma tributária segue sem que se toque no modelo regressivo de cobrança dos impostos no Brasil, que incide sobre os mais pobres e libera de responsabilidade os mais riscos. Mas tem a segunda linha. Ao expor a vulnerabilidade e a necessidade de abordagens dos problemas que vão além do escopo individual, a pandemia revela muito do que somos, das sociedades em que vivemos. Revela a vulnerabilidade de cada um, a fragilidade do humano. Os recursos para lidar com essa vulnerabilidade são, sem dúvida, diferenciados. Mas as desigualdades se revelam como fragilidade social, a ausência de investimentos públicos e de responsabilidade dos governantes se revelam como problemas que atingem a todos, ainda que em graus e de formas diferenciadas. Dessa tensão entre as desigualdades que se revelam e se tornam mais

\footnotetext{
10 Disponível em: < https://www1.folha.uol.com.br/opiniao/2020/04/novo-coronavirusresponsabilidade-e-precariedade. shtml?origin=folha\# $>$.

11 Ver: <https://g1.globo.com/pa/para/noticia/2020/05/07/lockdown-no-para-tem-servicodomestico-como-essencial-contrariando-governo-federal-e-mpt.ghtml>. Ver também: https://g1.globo.com/pa/para/noticia/2020/05/07/apos-criticas-decreto-de-lockdown-no-pararestringe-servico-domestico-liberado.ghtml>.
} 
INTER-LEGERE | Vol. 3, n. 28/2020: c22555 | ISSN 1982-1662 agudas e a capacidade de enxergarmos a nós mesmos como parte de coletividades, reposicionando o Estado e a noção de responsabilidade pública, podem fortalecer-se projetos, alianças, solidariedades, horizontes políticos. Sem querer resumir a situação tão complexa, diria que as pressões pela privatização (do que é público e dos problemas e responsabilidades) e as pressões pela politização e percepção do nosso destino comum foram, as duas e embora tenham sentidos distintos, potencializadas pela pandemia.

6. Outra questão se refere aos aspectos mais estruturantes de um universo de produção científica no campo das Ciências Humanas. Ora, sabemos que o Brasil atravessa um período de grande crise democrática simultânea à crise pandêmica e um dos efeitos imediatos têm sido sobre o campo de estudos das Ciências Humanas, pois temos recebido frequente descrédito sobre o que produzimos em matéria de conhecimento científico e, muitas vezes, sofremos ataques no sentido de rebaixar, desqualificar e censurar a soberania da atividade intelectual e acadêmica da referida área de conhecimento. Para exemplificar, duas questões presentes na esfera pública, facilmente encontradas em comentários de fóruns virtuais, podem resumir bem a pergunta: "qual a importância de formar profissionais nessa área?" e "para o que serve ciências humanas (ciências sociais)?", sempre articuladas com fins de hierarquizar e reivindicar um fim meramente utilitarista para o conhecimento científico. Contudo, "sem os conhecimentos das Ciências Humanas não é possível entender a sociedade", conforme afirma a cientista política Danielle Allen, professora da Harvard University ${ }^{12}$. Pensando nisso, gostaríamos que a senhora falasse principalmente do lugar de autoria das mulheres nas ciências humanas e ciências sociais.

A pandemia nos atinge quando o pensamento instrumental deixou de ser característica dos círculos liberais tecnocráticos e passou a ser mobilizado por forças de extrema-direita como forma de justificar a recusa ao conhecimento e realizar a supressão da crítica. Em todo o mundo, os processos de privatização da educação e

\footnotetext{
12 Ver: <https://www.bbc.com/portuguese/brasil-48070180>.
} 
INTER-LEGERE | Vol. 3, n. 28/2020: c22555 | ISSN 1982-1662 de abordagem utilitária desta e da ciência já produziam resultados: desvalorização de professores e da produção científica não orientada mercadologicamente, educação voltada para produzir “capital humano”, gente que vale mais que outros em mercados competitivos. Mas agora estamos diante de ataques abertos, que vêm dessa convergência complexa entre a racionalidade econômica e o autoritarismo de raízes também conservadoras. O Brasil se tornou um caso típico. Aqui, o ataque à Ciência, que é mais agudo no caso das Humanidades e das Ciências Sociais, vem na forma da desvalorização de sua relevância para o país (por que bancar pesquisa básica?), de reação à crítica social (por que a maioria deveria prover fundos para pesquisas que estão em desacordo com as tradições morais cristãs?), de estigmatização de docentes e estudantes, em uma clara aposta na ignorância e nas hierarquias que constituem uma ordem desigual e violenta. Observem que as bases do sistema de ciência e tecnologia brasileiro construído ao longo de décadas vão sendo desconstruídas pelo desinvestimento, pela instrumentalização (as áreas prioritárias definidas para financiamentos e bolsas de pesquisa) e pela recusa autoritária da crítica e do pluralismo (o rechaço a pesquisas sobre as relações de gênero, sobre a história política recente etc, definidas como “ideológicas”). Em meio a tudo isso, na rotina da pesquisa acadêmica, lidamos também com os efeitos da pandemia. É nesse ponto que os problemas políticos se cruzam com aqueles que, no cotidiano, organizam diferentemente o acesso a tempo e a recursos segundo o gênero, mas também a região do país em que pesquisadoras e pesquisadores se encontram. É preciso discutir o elitismo na academia, as formas de reprodução de hierarquias e de uma homogeneidade que existe à custa do futuro de jovens negras e negros, ao mesmo tempo que discutimos os ataques autoritários. Precisamos ao mesmo tempo nos preservar e nos reiventar.

7. Em recente entrevista para Úrsula Passos do Jornal Folha de São Paulo, a antropóloga brasileira Debora Diniz afirmou “O mundo pós-pandemia vai ser um mundo em que os valores feministas vão fazer parte do nosso vocabulário comum"13. Embora concordemos com ela sobre termos atualmente na esfera

\footnotetext{
13 Ver: <https://www1.folha.uol.com.br/equilibrioesaude/2020/04/mundo-pos-pandemia-teravalores-feministas-no-vocabulario-comum-diz-antropologa-debora-diniz.shtml>.
} 
INTER-LEGERE | Vol. 3, n. 28/2020: c22555 | ISSN 1982-1662 pública brasileira uma efervescência de mulheres se autoafirmando feministas, também podemos sustentar aqui que há uma forte presença e atuação do conservadorismo que está muito enraizado nas instituições políticas do Brasil. Para finalizar, já deixando aqui o registro de um profundo agradecimento por sua disponibilidade, gostaríamos de contar com sua opinião acerca da possibilidade de um amanhecer feminista no Brasil e no mundo pós-pandemia.

O anoitecer da pandemia já é feminista (risos). A manutenção da vida em meio a seus trágicos efeitos, em um país no qual são ampliados pela irresponsabilidade e pela incapacidade políticas, também é feminista. A construção de alternativas para a política de morte do governo é feminista. E o amanhecer será feminista. O que quero dizer com isso? As mulheres e os valores e práticas mobilizados pelos feminismos são parte da construção de alternativas todos os dias, assim como das alternativas para o futuro. Isso significa que somos capazes de conter os conservadorismos e a política de morte? Sim e não. As ações cotidianas e as alianças e solidariedades que os feminismos ativam em todo o mundo são fundamentais, mas podem não ser suficientes se não formos capazes de fortalecer nossos projetos de um mundo mais justo em alianças mais amplas, com efeitos nos espaços institucionais. Os partidos precisam ser mais feministas. O Congresso precisa ser mais feminista. Cada Câmara de Vereadores, cada Assembleia Legislativa. O Judiciário. E se não forem também antirracistas, não serão capazes de tocar na dinâmica de reprodução da violência, de apropriação das energias e da vida, que faz girar a roda de uma sociedade extremamente desigual. Na minha percepção, o horizonte feminista é também de crítica ao capitalismo - porque não é possível lutar contra a banalização da vida sem colocar em questão as formas correntes de desumanização, desapropriação, roubo da dignidade. Estamos falando de um capitalismo que depende da precarização cada vez maior da vida, reduzindo as garantias para quem trabalha, o tempo do cuidado, o acesso à saúde e à dignidade ao envelhecer. As alternativas de justiça precisam ser balizadas por valores e práticas feministas e antirracistas - ou não serão alternativas de fato. Eu vejo o momento que vivemos como profundamente trágico e preocupante. Mas vejo também potencial para romper, renovar, refazer. 
INTER-LEGERE | Vol. 3, n. 28/2020: c22555 | ISSN 1982-1662

Gratas,

Andressa Morais

Lorena Moraes 